\title{
Acknowledgment of Gift to Psychonomic Society from the Estate of Melvin Leon Goldstein
}

The Governing Board of the Psychonomic Society wish to gratefully acknowledge the generous bequest of over $\$ 11,000$ from the estate of the late Melvin Leon Goldstein, professor of psychology at Indiana University at Kokomo and member of the Psychonomic Society.

Melvin Goldstein was born in New York City in 1927, and during World War II served in an army medical unit in the Pacific. He received his AB degree in English from New York University, an MS degree in psychology from Washington State University, and his $\mathrm{PhD}$ in psychology from the University of Mlinois. From 1960 to 1965 , he conducted research in psychology and physiology at the University of Illinois, Syracuse University, and the University of Wisconsin. He joined the faculty of Indiana University at Kokomo in 1965.

Dr. Goldstein's scientific interests and work lay primarily in the area of neural correlates of learning processes, but he also took particular pleasure in stimulating scientific curiosity among students and in directing those who were engaged in individual research projects. These interests led him to establish two laboratories at IUK - a physiological psychology lab for the study of central nervous system influences on learning and a behavioral animal lab for undergraduates.

Dr. Goldstein's gift to the Society will help to reduce the costs involved in the production of its journals, and thus will contribute further toward the communication of scientific research in psychology and allied sciences. 